\title{
Broken Wires Diagnosis Method Numerical Simulation Based on Smart Cable Structure
}

\author{
Sheng $\mathrm{LI}^{1 *}$, Min $\mathrm{ZHOU}^{2}$, and Yan $\mathrm{YANG}^{3}$ \\ ${ }^{1}$ National Engineering Laboratory for Fiber Optic Sensing Technology, Wuhan University of Technology, Wuhan, \\ 430070, China \\ ${ }^{2}$ Wuhan WUTOS Limited Company, Wuhan, 430223, China \\ ${ }^{3}$ Key Laboratory of Fiber Optic Sensing Technology and Information Processing, Ministry of Education, Wuhan \\ University of Technology, Wuhan, 430070, China \\ *Corresponding author: Sheng LI_Ｅ-mail: lisheng@whut.edu.cn
}

\begin{abstract}
The smart cable with embedded distributed fiber optical Bragg grating (FBG) sensors was chosen as the object to study a new diagnosis method about broken wires of the bridge cable. The diagnosis strategy based on cable force and stress distribution state of steel wires was put forward. By establishing the bridge-cable and cable-steel wires model, the broken wires sample database was simulated numerically. A method of the characterization cable state pattern which can both represent the degree and location of broken wires inside a cable was put forward. The training and predicting results of the sample database by the back propagation (BP) neural network showed that the proposed broken wires diagnosis method was feasible and expanded the broken wires diagnosis research area by using the smart cable which was used to be only representing cable force.
\end{abstract}

Keywords: Fiber optical Bragg grating sensor, bridge cable, broken wires diagnosis, smart cable, BP neural network

Citation: Sheng LI, Min ZHOU, and Yan YANG, "Broken Wires Diagnosis Method Numerical Simulation Based on Smart Cable Structure," Photonic Sensors, 2014, 4(4): 366-372.

\section{Introduction}

The cable is an important bearing component for long-span cable-stayed bridges. Rust and fracture are common diseases for cables, which may lead to the failure of cable and bridge accidents [1]. Therefore, monitoring the cable force state and diagnosing the potential disease of broken wires are of great significance to protect the safety of bridge operation. At present, nondestructive detection is the main means for broken wires diagnosis, including the methods based on magnetostriction effect, the eddy current effect, and magnetic effect. Other acoustic detection methods such as ultrasonic, solid acoustic and ray are still in the level of laboratory testing and expensive [2-5]. In addition, in theory measuring the internal stress distribution state of steel wires and cable force simultaneously can also provide the broken wires information. However, current cable force detection methods can only provide cable force information and are unable to measure the steel wires stress distribution state. The smart cable with embedded optical fiber Bragg grating (FBG) sensors is a structure [6] that can realize both bearing and sensing. Based on the large

Received: 10 April 2014 / Revised version: 4 September 2014

(C) The Author(s) 2014. This article is published with open access at Springerlink.com

DOI: $10.1007 / \mathrm{s} 13320-014-0196-\mathrm{x}$

Article type: Regular 
strain FBG sensors [7] that are fastened to the peripheral wires in the cable fabricating the stage and calibration relationship between the cable force and steel wires strain in the over tensioning stage, the smart cable can output both cable force and steel wires stress. Utilizing the above characters of the smart cable, the research will focus on a proposed broken wires diagnosis strategy, establishing a broken wires sample database based on the bridge-cable and cable-steel model by numerical simulating and finishing the diagnosis method verification by the back propagation (BP) neural network.

\section{Broken wires diagnosis method}

\subsection{Diagnosis basis}

As shown in Fig. 1, several large strain FBG sensors are fastened to the peripheral wires in the connection pipe region during the cable fabricating process. The large strain FBG sensor with a special encapsulation structure $[8,9]$ meets the working range requirement for the stay cable, which can endure a large strain close to $5000 \mu \varepsilon$ under the over tensioning stage and the maximum combined loads in the operational stage. Besides the large range, as shown in Fig. 2, the mechanical fasten means for the sensor ensures a long-term effectiveness of force transmission.

As shown in Fig. 3, taking a 430-meter-length smart cable working in JingYue Bridge for example, the strain sensors wavelength drift time history curves under the over tensioning stage is shown in Fig. 4. Six large strain FBG sensors and two temperature FBG sensors as temperature compensation are embedded inside the cable. From the curves, the stress distribution response of the monitored steel wires shows a little nonuniformity. However, all FBG strain sensors meet the over tensioning loading requirement. The calibration relationship between the cable force and steel wires stress delegated by FBG strain sensors wavelength response is established in the over tensioning process. Thus, the smart cable can be used as the research basis for broken wires diagnosis through the cable force and steel wires stress distribution.

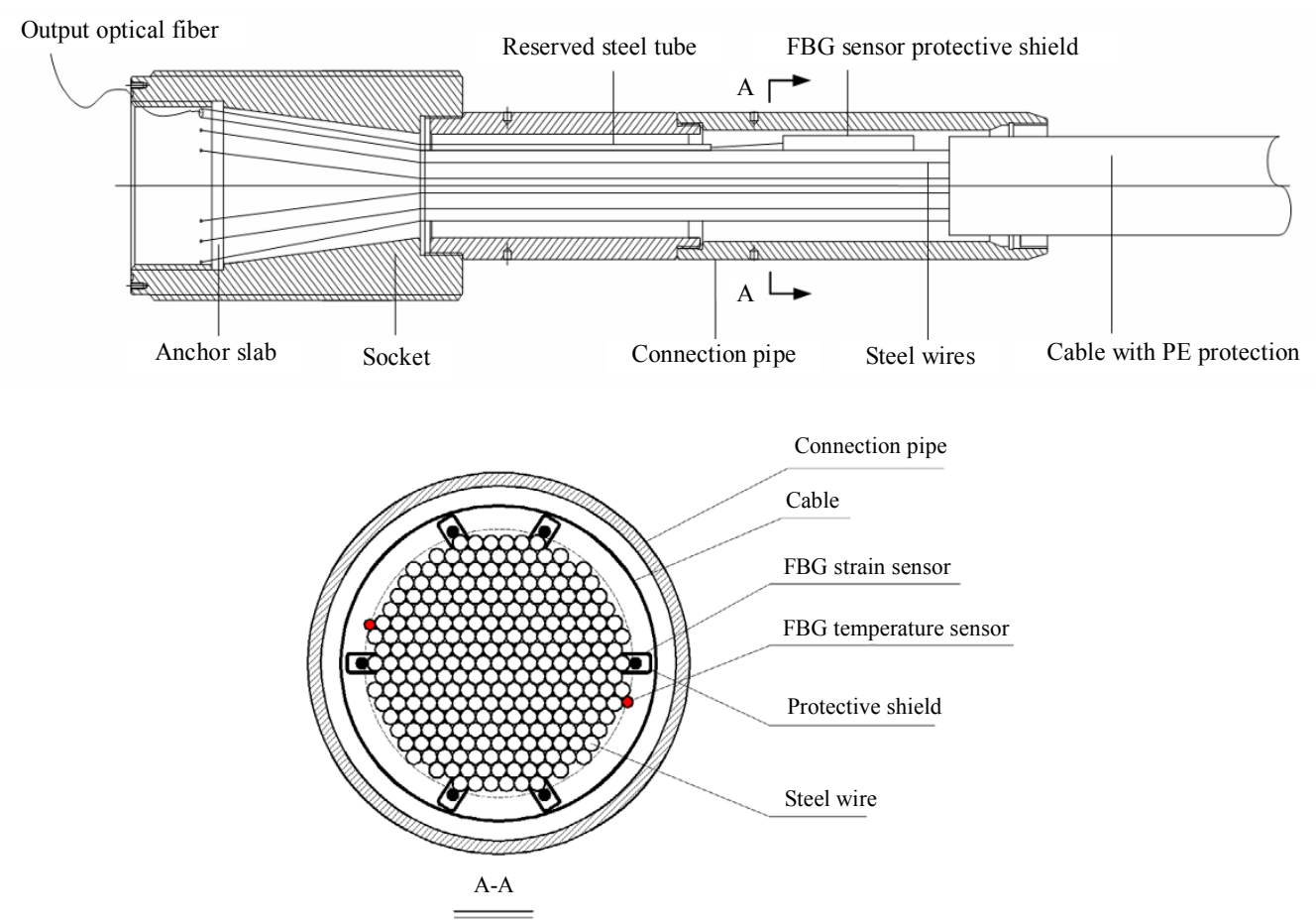

Fig. 1 Structure of the smart cable with embedded FBG sensors. 


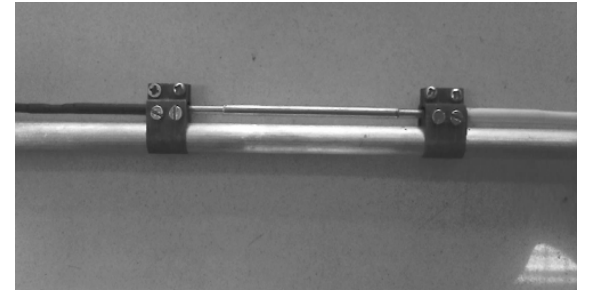

Fig. 2 Mechanical fasten between the sensor and cable steel wire.

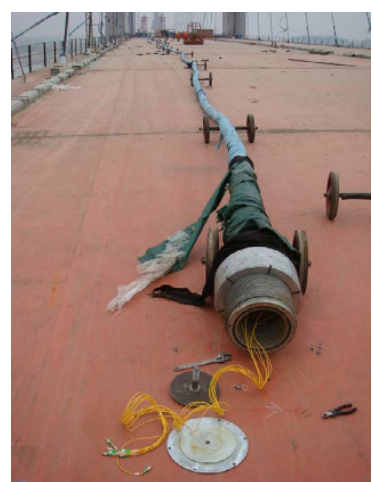

Fig. 3 Smart cable used in real bridge engineering.

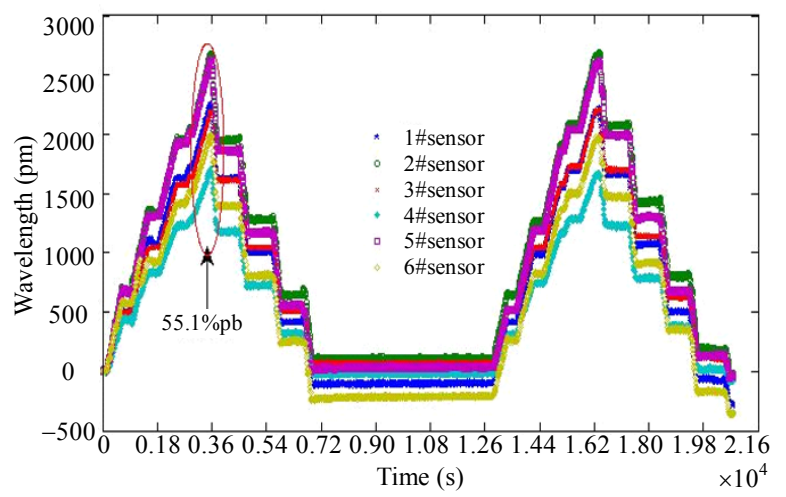

Fig. 4 FBG strain sensors wavelength drift of the smart cable under the over tensioning stage.

\subsection{Diagnosis strategy}

The input and output information composes the pattern recognition sample database for the broken wires. The input information includes the cable force and steel wires stress distributions under various combination load cases. The output information is a vector that can reflect the degree and location of broken wires inside the cable. The complete broken wires sample database is derived from the numerical model which considers the typical environment and vehicle loading according to bridge vulnerability analysis. The diagnosis strategy process is shown in Fig. 5. The FBG-based smart cable provides the input information, namely, cable force and stress distributions of the monitored steel wires. The establishment for the output information should consider the number and layout of embedded large strain FBG sensors inside the smart cable. The broken wires forecasting model is established by training the BP neural network based on the above proposed input and output indexes.

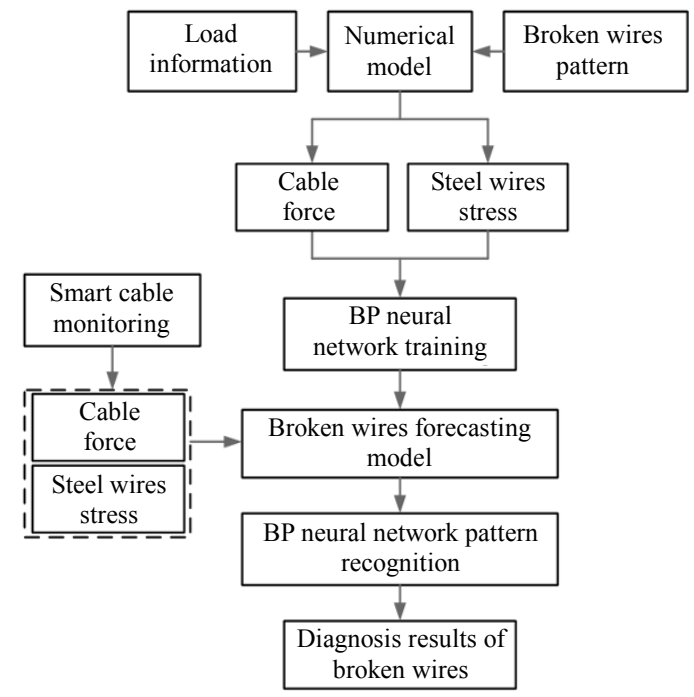

Fig. 5 Diagnosis strategy of broken wires inside a cable.

\section{Numerical simulation}

\subsection{Numerical model establishment}

A two-dimensional structure size cable-stayed bridge is used in [10] as the numerical simulation model basis. The structure material and geometric parameters are shown in Table 1. In order to simplify analysis, all stay cables in the model adopt the same specification (55 $\phi 7$ parallel steel wires stay cable). The sizes of the bridge-cable model and numerical analysis model are shown in Fig. 6.

Table 1 Structure material and geometric parameters.

\begin{tabular}{ccccc}
\hline Item & Beam & Pylon & Cable & Pier \\
\hline $\begin{array}{c}\text { Modulus of } \\
\text { elasticity }(\mathrm{MPa})\end{array}$ & $2.10 \mathrm{E}+05$ & $3.20 \mathrm{E}+04$ & $1.95 \mathrm{E}+05$ & $3.40 \mathrm{E}+04$ \\
Poisson's ratio & 0.2 & 0.167 & 0.2 & 0.167 \\
$\begin{array}{c}\text { Density }\left(\mathrm{kg} / \mathrm{m}^{3}\right) \\
\text { Moment of }\end{array}$ & 7850 & 2500 & 7850 & 2500 \\
$\begin{array}{c}\text { inertia } I_{z z}\left(\mathrm{~m}^{4}\right) \\
\text { Moment of }\end{array}$ & 5.26 & 21.33 & $/$ & 3.97 \\
$\begin{array}{c}\text { inertia } I_{y y}\left(\mathrm{~m}^{4}\right) \\
\text { Section area }\left(\mathrm{m}^{2}\right)\end{array}$ & 0.38 & 21.33 & $/$ & 3.97 \\
\hline
\end{tabular}




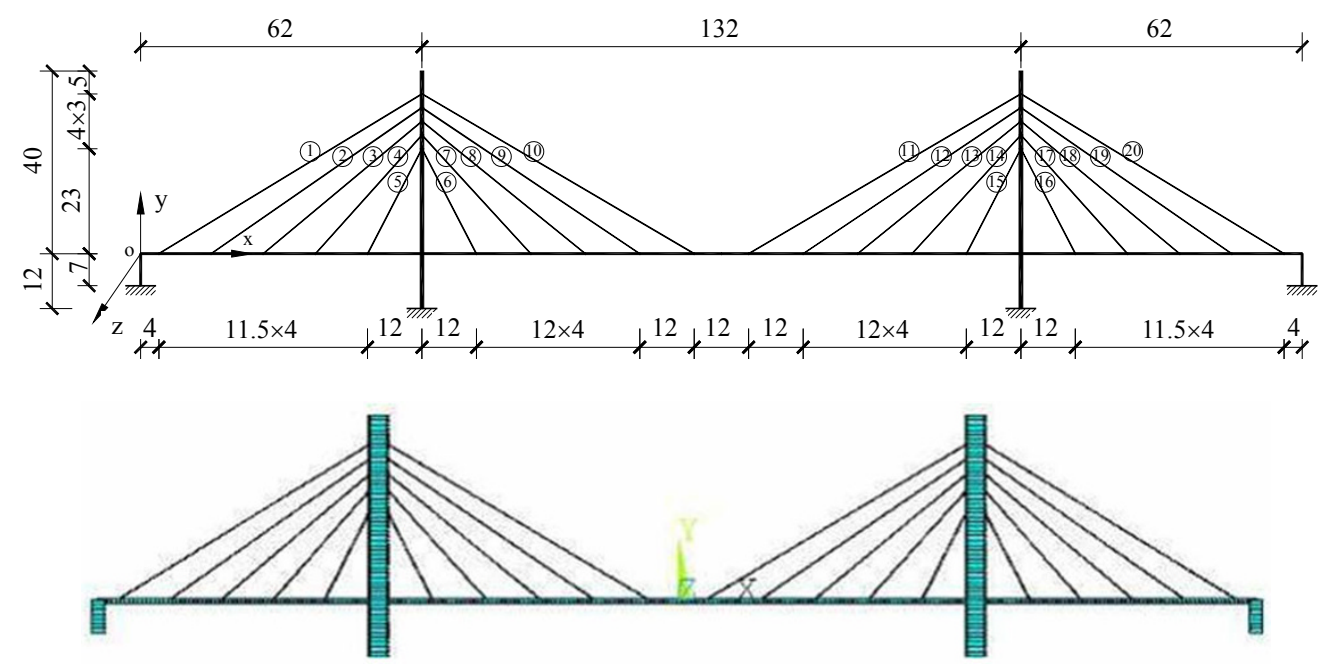

Fig. 6 Sizes of the bridge-cable model and numerical analysis model (unit: m).

It is necessary for establishing the cable-steel wires local model to analyze the relationship between the cable force and stress distributions of the monitoring steel wires. If using helix to simulate $2^{\circ}$ to $4^{\circ}$ twisting angle of outermost layer steel wires, it will consume large number of nodes to form a lay length. Figure 7(a) shows a one-sixth lay length cable model which divides a lay length into 6 segments. With an increase in the mesh precision, each steel wire will use a number of truss elements. To improve the numerical simulation efficiency, assuming the cable steel wires completely parallel, the simplified model is used as shown in Fig. 7(b) instead of the real helix model. The assumption is convenient for selecting the steel wire element, saving computing nodes, and does not change the steel wires stress distribution at each cable section compared with the real model in the cable length direction.

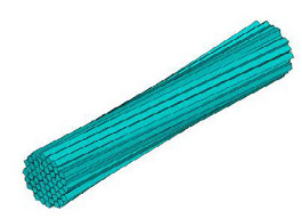

(a) real model

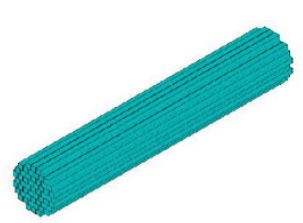

(b) simplified model
Fig. 7 Numerical analysis model of cable-steel wires.

\subsection{Broken wires sample database design}

The Chinese code [11] points out that a new cable must be replaced if the number of broken wires in the cable is more than $2 \%$. According to the proportion requirement, the numerical simulation for broken wires degree mainly considers 1 to 2 steel wires breaking for the $55 \phi 7$ parallel steel wires stay cable. Owing to verifying the effect of diagnosis strategy for broken wires, as shown in Fig. 8, the numerical simulation only considers the broken wires occurring in the peripheral steel wires under the dead load and assumes that the monitored steel wires attached to FBG strain sensors aren't broken and are only used to reflect the stress distribution at different broken wires states. Other complicated broken wires combination sample databases are omitted here.

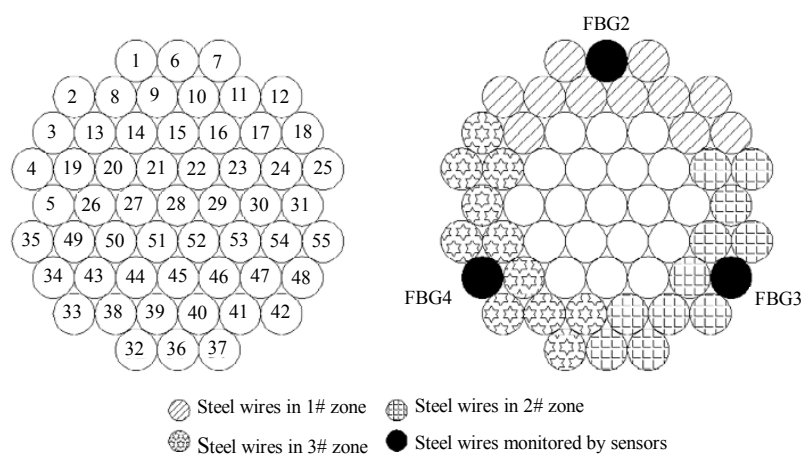

Fig. 8 Number of the section steel wires and defined zone.

Based on the above assumptions, according to the requirements for the damage identification steps, the aims of diagnosis strategy include correctly identifying whether broken wires occurs or not, the number of broken wires, namely, 1 or 2 steel wires 
breaking, and corresponding regional location. Taking the 10\# cable as the study object, by numerical calculation based on the bridge-cable model, Table 2 shows the cable force and steel wires average stress under the entire and broken state.

Table 2 Force of 10\# cable under structural dead load.

\begin{tabular}{cccc}
\hline \multirow{2}{*}{ Item } & \multicolumn{3}{c}{ Number of broken wires } \\
& 0 & 1 & 2 \\
\hline Force $(\mathrm{kN})$ & 87599 & 86149 & 84696 \\
Average stress $(\mathrm{MPa})$ & 41.39 & 41.46 & 41.52 \\
\hline
\end{tabular}

The defined distribution of the broken wires region and serial number of steel wires are shown in Fig. 8. There are three FBG strain sensors used for sensing the cable force and stress distributions. The broken wires region is divided into 3 zones. When there is one steel wire breaking, the database considers all steel wires in the defined region except for the monitored steel wires, totally setting $11+11+11=33$ samples. When there are two steel wires breaking, owing to the large number of sample combination, the database considers a special situation in which steel wires breaking occurs in the outermost layer and each region only has one steel wire breaking, totally setting $5 \times 5+5 \times 5+5 \times 5=75$ samples.

Thus, the number of simulation samples is 109 including an entire state with no broken wires. For the input information, FBG 1 represents the average stress derived from the smart cable force, and FBG 2 - FBG 4 represent the stress distributions derived from the steel wires monitored by FBG strain sensors. For the output information, seven vectors are defined, namely, entire state $\left(\begin{array}{lll}0 & 0 & 0\end{array}\right)$, one steel wire breaking in $1 \#$ zone $\left(\begin{array}{lll}1 & 0 & 0\end{array}\right)$, one steel wire breaking in $2 \#$ zone $\left(\begin{array}{lll}0 & 1 & 0\end{array}\right)$, one steel wire breaking in $3 \#$ zone $\left(\begin{array}{lll}0 & 0 & 1\end{array}\right)$, two steel wires breaking separately in $1 \#$ zone and 2\# zone ( 1100$)$, two steel wires breaking separately in $2 \#$ zone and $3 \#$ zone $(0$ $11)$, two steel wires breaking separately in $1 \#$ zone and $3 \#$ zone $\left(\begin{array}{lll}1 & 0 & 1\end{array}\right)$. Because only two types of broken wires degree are considered, the output vectors not only represent the broken wires region, but also distinguish the broken wires degree. Table 3 gives part of the sample database.

Table 3 Sample database of broken wires inside the cable.

\begin{tabular}{ccccccc}
\hline \multicolumn{2}{c}{ Number } & \multicolumn{5}{c}{ Input } \\
$\begin{array}{c}\text { Steel } \\
\text { wire }\end{array}$ & Sample & FGB1 & FBG2 & FBG3 & FBG4 & Output \\
\hline Entire & 1 & 41.39 & 41.41 & 41.37 & 41.37 & 000 \\
1 & 2 & 41.46 & 47.39 & 37.56 & 42.42 & 100 \\
$\ldots$ & $\ldots$ & $\ldots$ & $\ldots$ & $\ldots$ & $\ldots$ & $\ldots$ \\
25 & 13 & 41.46 & 42.17 & 43.42 & 38.93 & 010 \\
$\ldots$ & $\ldots$ & $\ldots$ & $\ldots$ & $\ldots$ & $\ldots$ & $\ldots$ \\
32 & 24 & 41.46 & 38.97 & 42.12 & 43.41 & 001 \\
$\ldots$ & $\ldots$ & $\ldots$ & $\ldots$ & $\ldots$ & $\ldots$ & $\ldots$ \\
$1+25$ & 35 & 41.52 & 44.88 & 41.62 & 38.40 & 110 \\
$\ldots$ & $\ldots$ & $\ldots$ & $\ldots$ & $\ldots$ & $\ldots$ & $\ldots$ \\
$2+32$ & 60 & 41.52 & 40.99 & 39.69 & 44.04 & 101 \\
$\ldots$ & $\ldots$ & $\ldots$ & $\ldots$ & $\ldots$ & $\ldots$ & $\ldots$ \\
$25+32$ & 109 & 41.52 & 39.74 & 44.04 & 40.94 & 011 \\
\hline
\end{tabular}

\subsection{Diagnosis effective evaluation}

The sample database training is finished by the BP neural network, which uses three-layer network structure. The stress distrubitions expressed by FBG 1 to FBG 4 that shown in Table 3 are used as the input layer. The hidden layer adopts the S-shaped tangent transfer function with 14 neurons decided by practical training effect, and the output layer adopts the S-shaped logarithmic transfer function.

Three samples of one steel wire breaking and six samples of two steel wires breaking compose the test sample database. The other 100 samples including the entire state are used for model training. In order to improve the training convergence efficiency, based on (1), normalization for the input data is processed, which uses all input data in the numerical interval $[0,1]$ :

$$
\hat{x}=\frac{x-x_{\text {min }}}{x_{\text {max }}-x_{\text {min }}} \text {. }
$$

After 45 steps, network learning error satisfies the training target. According to (2), two types of noise level are considered to simulate the measurement error, where $p_{i}$ is the input data 
polluted by noise; $p_{i}^{a}$ is the original input data derived by numerical simulation; $\varepsilon$ is the noise level expressed by percentage $(1 \%$ and $5 \%$ noise levels are considered, respectively); $R$ is an average distribution random variable in the numerical interval $[-1,1]$.

$$
p_{i}=p_{i}^{a}(1+\varepsilon R) \text {. }
$$

As shown in Table 4, "(O)" represents that all recognition results are correct, and " $\mathrm{x}$ " represents that partial recognition results are feasible or except for the expecting recognition results there are misreport results. Before applying noise, recognition results are totally correct, which can predict both the degree and location of the broken wires. After applying noise, the recognition accuracy rate decreases which is due to noise pollution and the incompleteness of the training sample database for broken wires. The total number of the broken wires is 15 for the 9 test samples. Under the $1 \%$ noise level, the predicted 13 broken wires at the right region are recognized with no misreport and $86.7 \%$ accuracy rate for the 9 test samples. Under the 5\% noise level, 12 broken wires for the 9 test samples are predicted, but among the recognition results there are 2 misreports occurred for 1 and 2 broken wires situation, respectively. If taking misreport as prediction failure, only 10 broken wires are recognized successfully with $66.7 \%$ accuracy rate for the 9 test samples. Thus, the overall accuracy rate for diagnosing broken wires is more than $60 \%$ under the $5 \%$ noise level interference. cable.

Table 4 Testing sample and result of broken wires inside the

\begin{tabular}{cccc}
\hline Test sample number & \multicolumn{3}{c}{ Output } \\
& no noise & $1 \%$ noise & $5 \%$ noise \\
\hline 3 & 0 & 0 & 0 \\
15 & 0 & 0 & $\mathrm{x}$ \\
26 & 0 & 0 & 0 \\
47 & 0 & 0 & 0 \\
53 & 0 & $\mathrm{x}$ & $\bigcirc$ \\
71 & 0 & $\mathrm{x}$ & $\mathrm{x}$ \\
63 & 0 & 0 & $\mathrm{x}$ \\
97 & 0 & 0 & $\bigcirc$ \\
103 & 0 & 0 & $\mathrm{x}$ \\
\hline
\end{tabular}

\section{Conclusions}

A broken wires diagnosis strategy that using cable and stress distributions as indexes and BP neural network as the pattern recognition method is proposed based on the characters of the FBG-based smart cable which can reflect both force and stress distributions of steel wires. The feasibility of the proposed diagnosis method which considers noise interruption is verified by the numerical simulation sample database derived from the bridge-cable and cable-steel wires numerical analysis model. The results show that proposed strategy can provide a new way for the bridge engineering broken wires diagnosis.

\section{Acknowledgment}

The research work reported in this paper was supported by the National Engineering Laboratory for Fiber Optic Sensing Technology, Wuhan University of Technology, China. Thanks for the support of the Fundamental Research Funds for the Central Universities (WUT: 2014-IV-090) and the National Natural Science Foundation of China (Major Program: 61290310).

Open Access This article is distributed under the terms of the Creative Commons Attribution License which permits any use, distribution, and reproduction in any medium, provided the original author(s) and source are credited.

\section{References}

[1] J. Zhang and W. Wang, Manual of bridge inspection and reinforcement. Beijing: China Communication Press, 2007.

[2] J. Ye, "Discussion on fracture of steel wires for cable," Steel Construction, 2003, 18(65): 35-36, 45.

[3] X. Wu, J. Wang, and S. Yang, "Development of a testing system for detecting the defect in diagnoal bridge cable," Mechanical Science and Technology, 2001, 20(6): 901-903.

[4] X. Wu, Yi. Kang, and H. Chen, "Nondestructive testing method and technique for cable-stayed bridge steel cables," Key Engineering Materials, 2004, 270-273(7): 1493-1499. 
[5] M. Cooper, "Radiographic examination of wire ropes suspension cables," Materials Evaluation, 1992, 50(12): 1383-1384, 1388.

[6] S. Li, D. Jiang, and X. Zhao, "Desensitized encapsulation FBG sensor for smart cable in bridge," in 22nd International Conference on Optical Fiber Sensors (OFS22), Beijing, China, October 15-19, 2012.

[7] S. Li and D. Jiang, "Structural large strain monitoring based on FBG sensor," in Symposium on Photonics and Optoelectronics (SOPO2009), Wuhan, China, August 14-16, 2009.

[8] D. Jiang, S. Li, L. Liu, S. Liu, E. Zhang, and X. Zhao, "Fiber optical Bragg grating strain sensor for smart cable," Chinese Patent ZL200920188144.9, September 1, 2010

[9] S. Li and M. Zhou, "Long-term mechanical properties of smart cable based on FBG desensitized encapsulation sensors," Photonic Sensors, 2014, 4(3): 236-241.

[10] Q. Zhang, Q. Li, and L. Tang, "Study on structural damage location identification by damage indices for cable-stayed bridges," Engineering Mechanics, 2008, 25(5): 163-169.

[11] Ministry of construction of the People's Republic of China, Technical code of maintenance for city bridge CJJ99-2003. Beijing: China Architecture \& Building Press, 2003. 